\title{
TINGKAT PENGETAHUAN PASIEN TENTANG PERAWATAN GASTRITIS DI RS UMUM BANGKATAN BINJAI TAHUN 2016
}

\author{
Patient's Knowledge Level About Gastritical Care at Bangkatan \\ General Hospital Year 2016
}

\author{
Ilham Syahputra Siregar ${ }^{1}$ \\ ${ }^{1}$ Dosen Akademi Keperawatan Sehat Binjai \\ E-mail: ilhamsyahputra0219@gmail.com
}

\begin{abstract}
Abstrak
Gastritis merupakan peradangan yang mengenai mukosa lambung. Peradangan ini dapat mengakibatkan pembekakan mukosa lambung sampai terlepasnya epitel mukosa superficial yang menjadi penyebab terpenting dalam gangguan saluran pencernaan. Pelepasan epitel akan merangsang timbulnya proses inflamasi pada lambung.

Gastritis atau dyspepsia atau istilah yang di kenal oleh masyarakat sebagai maag atau penyakit lambung adalah kumpulan gejala yang di rasakan sebagai nyeri terutama di ulu hati,orang yang terserang penyakit ini biasanya sering mual,muntah, rasa penuh dan rasa tidak nyaman. Penyebab gastritis adalah pemakaian obat antiinflamasi nonstrerois seperti aspirin, asam mafenamat, dalam jumlah besar, konsumsi alcohol berlebih, banyak merokok, pemeriksaan kemotrapi, stress berat, konsumsi kimia peroral yang bersifat asam basa dan iskemik syok. Pelaksanaan penelitian ini bertujuan untuk mengetahui tingkat pengetahuan pasien tentang perawatan gastritis (maag).

Metode penelitian yang digunakan adalah metode deskriptif kuantitatif, pengambilan sampel denga menggunakan teknik accidental sampling. Sebanyak 30 orang dengan instrument pengumpulan data berupa quesioner. Data yang diperoleh dikelompokkan berdasarkan tingkat pengetahuan pasien tentang penyakit gastritis.

Berdasarkan tingkat pengetahuan pasien tentang perawatan gastritis adalah baik 13 orang (43\%), cukup 12 Orang (40\%), dan kurang sebanyak 5 orang (17\%) sehingga dapat disimpulkan bahwa pengetahuan pasien tentang perawatan gastritis di Rumah Sakit Umum Bangkatan Kota Binjai tergolong baik. Tetapi tidak di terapkan dalam kehidupan sehari-hari.
\end{abstract}

Kata kunci : Pengetahuan Pasien, Gastritis, Perawatan Gastritis.

\begin{abstract}
Gastritis is an inflammation that affects the gastric mucosa. This inflammation can result in coagulation of the gastric mucosa until the release of the superficial mucosal epithelium is the most important cause of digestive tract disorders. Epithelial release will stimulate the onset of the inflammatory process in the stomach.

Gastritis or dyspepsia or a term known by the community as an ulcer or stomach disease is a collection of symptoms that are felt as pain, especially in the pit of the stomach, people who are attacked by this disease are usually often nausea, vomiting, feeling full and feeling uncomfortable. The cause of gastritis is the use of non-steroidal anti-inflammatory drugs such as aspirin, mafenamat acid, in large quantities, excessive alcohol consumption, lots of smoking, chemotherapy testing, severe stress, consumption of oral chemicals that are acid-base and ischemic shock. The purpose of this study is to determine the level of patient's knowledge about the treatment of gastritis (ulcer).

The research method used is descriptive quantitative method, taking samples using accidental sampling techniques. As many as 30 people with questionnaire data collection instruments. The data obtained are grouped based on the level of patient's knowledge of gastritis.

Based on the level of knowledge of patients about gastritis treatment, there were 13 people (43\%), quite 12 people (40\%), and less as many as 5 people (17\%) so that it can be concluded that the patient's knowledge of gastritis treatment at Binjai City General Hospital is classified well. But it is not applied in everyday life.
\end{abstract}

Keywords: Patient Knowledge, Gastritis, Gastritis Treatment. 


\section{PENDAHULUAN}

Gastritis merupakan peradangan atau pembengkakan dari mukosa lambung yang disebabkan oleh faktor iritasi dan infeksi. Bahaya penyakit gastritis jika dibiarkan terus-menerus akan merusak pungsi lambung hingga menyebabkan kematian. Berbagai penelitian menyimpulkan bahwa keluhan sakit pada penyakit gastritis paling banyak ditemui akibat gastritis fungsional, yaiu mencapai $70-80 \%$ dari seluruh kasus. Gastritis fungsional merupakan sakit yang bukan disebabkan oleh ganguan pada organ lambung melainkan lebih sering dipicu oleh pola makan yang kurang sesuai, faktor psikis dan kecemasan (Saydam, 2011). Gasrtitis adalah inflamasi pada lapisan mukosa dan sub mukosa lambung. Secara histologist dapat dibuktikan dengan adanya inflamasi sel-sel radang pada daerah tersebut. Pada manifestasi klinis dapat dibagi menjadi akut dan kronis (Hirlan, 2001). Menurut Brunner dan Sudarth (2003) menjelaskan bahwa pengertian gastritis adalah gangguan yang terjadi dengan karakteristik adanya anoreksia, rasa penuh, dan tidak enak pada efigastrium, mual, muntah.

Berdasarkan penelitian World Health Organization (WHO) terhadap beberapa negara di dunia, mendapati bahwa jumlah penderita gastritis di Negara Inggris $22 \%$, China $31 \%$, Jepang $14,5 \%$, Kanada $35 \%$ dan Perancis 29,5\% (WHO, 2010).

Penderita gastritis di Indonesia menurut WHO adalah 40,8\%. Angka kejadian gastritis pada beberapa daerah di Indonesia cukup tinggi dengan prevalensi 274.396 kasus dari 238.452.952 jiwa penduduk.

Berdasarkan hasil survei pendahuluan peneliti pada lokasi penelitian, masih banyak pasien yang dirawat di Rumah Sakit Umum Bangkatan Binjai yang belum mengetahui tentang perawatan penyakit gastritis. Menurut data Rumah Sakit Umum Bangkatan Binjai Pasien gastritis di Rumah Sakit Umum Bangkatan Binjai pada tahun 2017 sebanyak 30 pasien gastritis tiap bulannya.

Kejadian gastritis ini apabila tidak segera ditangani akan dapat menimbulkan akibat atau penyakit-penyakt lain, seperti akibat yang dapat ditimbulkan dari gastritis akut berupa perdarahan saluran cerna bagian atas (SCBA), hematemesis dan melana, yang berakhir dengan shock hemoragik. Namun, apabila prosesnya hebat, sering juga terjadi ulkus tetapi jarang terjadi perforasi.

Akibat lain yang dapat ditimbulkan dari gastritis kronis yaitu gangguan penyerapan vitamin B12. Penyerapan vitamin B12 yang kurang dapat menyebabkan timbulnya anemia pernesiosa, gangguan penyerapan zat besi, dan penyempitan daerah pylorus (pelepasan dari lambung ke usus dua belas jari) (Muttagin dan Sari, 2011). Penyakit gastritis bila dibiarkan terus-menerus akan merusak pungsi lambung dan dapat mengakibatkan resiko terjadiya keganasan lambung yan berujung pada kematian (Muttagin, \& kawan-kawan, 2011).

Berdasarkan uraian di atas maka peneliti tertarik untuk melakukan penelitian yang berjudul Tingkat Pengetahuan Pasien Tentang Perawatan Gastritis Di Rumah Sakit Umum Bangkatan Binjai Tahun 2016.

\section{METODE}

Rancangan yang digunakan dalam penelitian ini adalah deskriptif yaitu metode penelitian yang dilakukan dengan tujuan utama untuk membuat gambaran atau deskriptif tentang suatu keadaan secara objektif (Notoadmodjo, 2007).

Penggunaan desain deskriptif untuk mengetahui mengetahui tingkat Pengetahuan Pasien Tentang Perawatan Gastritisdi Rumah Sakit Umum Bangkatan Binjai Tahun 2016. Lokasi penelitian ini adalah di Rumah Sakit Umum Bangkatan Binjai. Penelitian ini dimulai bulan Januari 2016 dengan kegiatan penelusuran pustaka, mengajukan judul, survey penelitian, bimbingan kegiatan dan seminar proposal penelitian. Pada penelitian ini, populasinya adalah seluruh pasien yang menderita gastritis. Dari hasil survey ditemukan pasien gastritis sebanyak 30 orang di Rumah Sakit Umum Bangkatan Binjai. 


\section{HASIL PENELITIAN}

Tabel 1. Distribusi Frekuensi Responden berdasarkan kelompok Umur Di RS Umum Bangkatan Binjai Tahun 2016

\begin{tabular}{cccc}
\hline No. & $\begin{array}{c}\text { Kelompok } \\
\text { Umur } \\
\text { (tahun) }\end{array}$ & Jumlah & Persentase \\
\hline 1. & $17-25$ & 16 & $53 \%$ \\
2. & $26-33$ & 8 & $27 \%$ \\
3. & $34-40$ & 6 & $20 \%$ \\
\hline & Jumlah & $\mathbf{3 0}$ & $\mathbf{1 0 0 \%}$ \\
& & Orang & \\
\hline
\end{tabular}

Dari tabel di atas dapat dilihat bahwa responden penelitian berdasarkan umur terbanyak berumur 17-25 tahun 16 orang (53\%). Umur 26-33 tahun sebanyak 8 orang (27\%), dan umur 34-40 tahun sebanyak 6 orang $(20 \%)$.

Tabel 2. Distribusi Frekuensi Responden Berdasarkan Tingkat Pendidikan Di RS Umum Bangkatan Binjai Tahun 2016

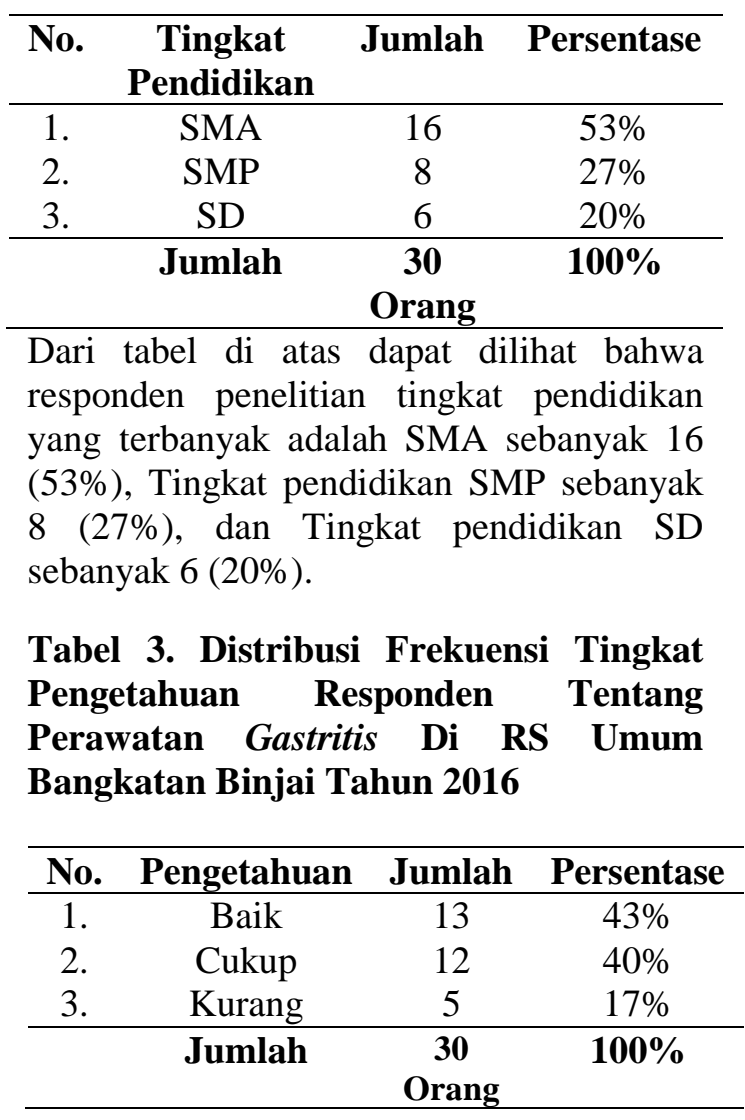

Dari tabel di atas dapat dilihat bahwa hasil tingkat pengetahuan pasien tentang perawatan gastritis di Rumah Sakit Umum Bangkatan Binjai yang berpengetahuan baik sebanyak 13 orang (43\%), cukup 12 Orang (40\%), dan kurang sebanyak 5 orang $(17 \%)$.

Tabel 4. Distribusi Frekuensi Tingkat Pengetahuan Responden Tentang Perawatan Gastritis Berdasarkan Farmakologi Di RS Umum Bangkatan Binjai Tahun 2016

\begin{tabular}{cccc}
\hline No & Pengetahuan & $\begin{array}{c}\text { Jumla } \\
\text { h }\end{array}$ & $\begin{array}{c}\text { Persenta } \\
\text { se }\end{array}$ \\
\hline 1. & Baik & 19 & $63 \%$ \\
2. & Cukup & 8 & $27 \%$ \\
3. & Kurang & 3 & $10 \%$ \\
& Jumlah & 30 & $\mathbf{1 0 0 \%}$ \\
& & Orang \\
\hline
\end{tabular}

Dari tabel di atas dapat dilihat hasil tingkat pengetahuan responden berdasarkan farmakologi di Rumah Sakit Umum Bangkatan Binjai yang berpengetahuan baik sebanyak 19 (63\%), cukup sebanyak 8 (27\%), dan kurang sebanyak 3 (10\%). Dari tabel diatas dapat dilihat hasil tingkat pengetahuan responden berdasarkan non farmakologi di Rumah Sakit Umum Bangkatan Binjai yang berpengetahuan baik sebanyak 12 (40\%), cukup sebanyak 10 (33\%), dan kurang sebanyak 8 (27\%)

\section{PEMBAHASAN}

Dalam penelitian ini yang menjadi responden adalah pasien yang berumur 1740 tahun yang ada di Rumah Sakit Umum Bangkatan Binjai. Penelitian ini bertujuan untuk mengetahui sejauh mana tingkat pengetahuan pasien tentang perawatan gastritis.

Dari tabel 4.1 setelah dianalisa data dan diinterprestasikan bahwa tingkat umur pasien di Rumah Sakit Umum Bangkatan Binjai adalah yang terbanyak berumur 1725 tahun yaitu sebanyak 16 orang (53\%), umur 26-33 tahun yaitu sebanyak 8 orang (27\%), dan umur 34-40 tahun sebanyak 6 orang $(20 \%)$. Umur adalah variabel yang selalu diperhatikan dalam penyelidikan- 
penyelidikan epidemiologi, selain itu angka-angka kematian didalam hampir semua keadaan menunjukan hubungan dengan umur (Notoatmodjo, 2007). Umur dalam hal ini berhubungan dengan kematangan berfikir seseorang dan pengalaman hidup seseorang terhadap sesuatu hal, semakin tinggi usia semakin banyak pengalaman yang didapat dalam kehidupan dan hal ini juga akan berpengaruh pada kematangan pola fikir seseorang dalam menanggapi masalah. Menurut Elizabeth (2012) Usia ini menunjukkan perubahan-perubahan fisik dan psikologis yang menyertai kurangnya kemampuan reproduktif.

Dari tabel 4.2 setelah dianalisa dan diinterprestasikan bahwa tingkat pendidikan tentang perawatan gastritis di Rumah Sakit Umum Bangkatan Binjai yang berpendidikan SMA sebanyak $16(53 \%)$, Tingkat pendidikan SMP sebanyak 8 (27\%), dan Tingkat pendidikan SD 6 (20\%). Hal ini menunjukan bahwa tingkat pendidikan berhubungan dengan pengetahuan pasien tentang perawatan gastritis di Rumah Sakit Umum Bangkatan Binjai.

Pendidikan merupakan penuntun untuk berbuat dan mengisi kehidupannya yang dapat digunakan untuk mendapat informasi sehingga dapat meningkatkan kualitas hidup. Sebagaimana umumnya, Semakin tinggi pendidikan seseorang semakin mudah menyampaikan atau pun menerima informasi dan makin bagus pengetahuan yang dimiliki seseorang sehingga penggunaan komunikasi, berbagai informasi akan mudah diterima jika bahasa yang disampaikan sesuai dengan tingkat pendidikan dan mudah dimengerti (Hidayat, 2008 ).

\section{HASIL PENGUKURAN KUISIONER}

Dari tabel 4.3 setelah dianalisa data dan diinterprestasikan bahwa tingkat pengrtahuan pasien tentang perawatan gastritis di Rumah Sakit Umum Bangkatan Binjai adalah yang berpengetahuan baik sebanyak 13 orang (43\%), cukup 12 0rang (40\%), dan kurang sebanyak 5 orang (17\%). Jadi, bahwa pengetahuan sangat berpengaruh terhadap kondisi tubuh seseorang. Hal ini dapat diketahui bahwa pasien harus menyempatkan diri untuk mengikuti penyuluhan dari tim kesehatan tentang pentingnya menjaga kesehatan terutama mengenai perawatan gastritis.

Dari hasil keseluruhan dapat diketahui bahwa pada umumnya responden memiliki pengetahuan baik tentang perawatan gastritis. Tapi, tidak di terapkan didalam kehidupan sehari-sehari. Dengan demikian responden berisiko kekambuhan penyakit gastritis. Angka kejadian infeksi gastritis pada beberapa daerah di Indonesia menunjukkan data yang cukup tinggi, di Surabaya angka kejadian gastritis sebesar $31,2 \%$, Denpasar 46\%, sedangkan di Sumatra utara angka kesakitan cukup besar 91,6\%. Faktor etiologi gastritis lainyan adalah asupan alcohol berlebihan (20\%), merokok (5\%), makanan berbumbu (15\%), dan obat - obatan (18\%) (Depkes, 2009).

\section{KESIMPULAN}

1. Distribusi frekuensi tingkat pengetahuan responden berdasarkan farmakologi di Rumah Sakit Umum Bangkatan Binjai yang berpengetahuan baik sebanyak 19 (63\%), cukup sebanyak 8 (27\%), dan kurang sebanyak 3 (10\%).

2. Distribusi frekuensi tingkat pengetahuan responden berdasarkan gaya hidup sehat di Rumah Sakit Umum Bangkatan Binjai yang berpengetahuan baik sebanyak 20 (67\%), cukup sebanyak 5 (17\%), dan kurang sebanyak 5 (17\%)

3. Distribusi frekuensi tingkat pengetahuan responden berdasarkan non farmakologi di Rumah Sakit Umum Bangkatan Binjai yang berpengetahuan baik sebanyak 12 (40\%), cukup sebanyak 10 (33\%), dan kurang sebanyak 8 (27\%)

4. Disrtibusi frekuensi tingkat pengetahuan responden tentang perawatan gastritis di Rumah Sakit Umum Bangkatan Binjai yang berpengetahuan baik sebanyak 13 orang (43\%), cukup 12 Orang (40\%), dan kurang sebanyak 5 orang (17\%).

\section{SARAN}

1. Disarankan untuk pasien yang berpengetahuan baik. Tetapi tidak mau menerapkannya dalam kehidupan sehari-sehari maka upaya peningkatan 
pengetahuan pasien tentang perawatan gastritis perlu di tingkatkan dengan cara formal maupun informal demi mencapai tingkat pengetahuan yang seoptimal mungkin khususnya pada pasien yang terkena penyakit gastritis.

2. Diharapkan dengan adanya penambahan informasi tersebut diharapkan pasien yang menderita penyakit gastritis dapat lebih memahami dan meningkatkan pengetahuan tentang perawatan gastritis.

3. Perlu adanya masukan dari dosen maupu dari buku tentang perawatan gastritis diantaranya bagaimana cara penanggulangan secara dini untuk mengatasi penyakit gastritis.

4. Bagi peneliti selanjutnya di harapkan agar lebih memahami dalam melaksanakan penelitian dan mempelajari riset keperawatan.

\section{DAFTAR PUSTAKA}

Arikunto. 2006. Konsep dan Penulisan Riset Keperawatan, Ghara Ilmu, Jakarta.

Chudahman, M. 2009. Mengenal penyakit organ cerna,pustaka popular obor, Jakarta.

Endang. 2012. Penyakit Maag dan Gangguan Pencernaan, kanisus, Yogyakarta.

Hidayat, A. Aziz Alimul. 2007. Riset Keperawatan Tehnik Penulisan Ilmiah,Selemba Medika, Jakarta.

Misnadiarly. 2008. Mengenal Penyakit Gastritis (Penyakit Maag), Pustaka Popular Obor, Jakarta.

Nurheti. 2009. Maag, Kenali, Hindaridan, Obati, Andi Offset, Yogyakarta.

Notoadmojo, S. 2012. Metedologi Penelitian Kesehatan, Rineka Cipta, Jakarta.

Rizem, A. 2016. Penyakit Orang Kantoran, Flash Books. Jakarta.

Saryono. 2011. Metodologi Penelitian Ksehatan, Mitra Cendikia Press, Jokjakarta

Simadibrata. R. 2010. Konsep mutakhir dalam diagnosis dan terapig gastritis, pustaka popular obor, Jakarta.

Sukarmin. 2012. Keperawatan Pada Sistem Pencernaan, Pustaka Pelajar Yogyakarta. 